\title{
Sleep disturbance in older ICU patients
}

This article was published in the following Dove Press journal:

Clinical Interventions in Aging

23 June 2014

Number of times this article has been viewed

\author{
Roxanne Sterniczuk ${ }^{1-3}$ \\ Benjamin Rusak ${ }^{1,2}$ \\ Kenneth Rockwood ${ }^{3}$ \\ 'Department of Psychology and \\ Neuroscience, Dalhousie University, \\ Halifax, NS, ${ }^{2}$ Department of \\ Psychiatry, Dalhousie University, \\ Queen Elizabeth II Health Sciences \\ Centre, Halifax, NS, ${ }^{3}$ Division \\ of Geriatric Medicine, Department \\ of Medicine, Queen Elizabeth II \\ Health Sciences Centre, Halifax, \\ NS, Canada
}

\begin{abstract}
Maintaining a stable and adequate sleeping pattern is associated with good health and disease prevention. As a restorative process, sleep is important for supporting immune function and aiding the body in healing and recovery. Aging is associated with characteristic changes to sleep quantity and quality, which make it more difficult to adjust sleep-wake rhythms to changing environmental conditions. Sleep disturbance and abnormal sleep-wake cycles are commonly reported in seriously ill older patients in the intensive care unit (ICU). A combination of intrinsic and extrinsic factors appears to contribute to these disruptions. Little is known regarding the effect that sleep disturbance has on health status in the oldest of old (80+), a group, who with diminishing physiological reserve and increasing prevalence of frailty, is at a greater risk of adverse health outcomes, such as cognitive decline and mortality. Here we review how sleep is altered in the ICU, with particular attention to older patients, especially those aged $\geq 80$ years. Further work is required to understand what impact sleep disturbance has on frailty levels and poor outcomes in older critically ill patients.
\end{abstract}

Keywords: intensive care unit, sleep-wake rhythm, aging, frailty

\section{Sleep and health}

Adequate sleep and stable sleep-wake cycles are important to maintaining good lifelong physical and mental health. Chronically disrupting sleep and deviating the natural sleep-wake rhythm from the normal 24-hour environmental cycle can contribute to various long-term health consequences, ${ }^{1}$ including obesity, ${ }^{2}$ cardiovascular disease,${ }^{3}$ and type 2 diabetes. ${ }^{4}$ In addition, disrupted sleep-wake rhythms (eg, chronic shift work) can strongly increase the risk for cancer. ${ }^{5,6}$ Sleep loss and disruption can also lead to weakened immune system function, ${ }^{7,8}$ diminished memory consolidation, ${ }^{9}$ disrupted neuroendocrine function, including changes in glucose metabolism, ${ }^{10-12}$ and cognitive decline, including a diagnosis of Alzheimer's disease. ${ }^{13,14}$ Not only does impaired sleep lead to the development of many illnesses, it is also associated with impaired healing and recovery, ${ }^{15-17}$ perhaps reflecting a further association with weakened immune system function. ${ }^{7,8}$ This type of problem - both predisposing to disease and impairing repair - is associated with accelerated health deficit accumulation, a problem for older adults, especially those who become acutely ill. ${ }^{18,19}$

\section{Sleep disturbance in older adults}

Aging has been traditionally associated with changes to sleep quantity, quality, and timing. Roughly 30\% of those 50 years and older may suffer from sleeping problems ${ }^{20-22}$ with more than $80 \%$ of those over 65 reporting some degree of disrupted sleep. ${ }^{23}$ This disruption can be reflected in increased nighttime restlessness and daytime sleepiness. Most notable is the phase advance of the sleep-wake cycle relative to 
external time: many older people tend to go to bed earlier and awaken much sooner than younger adults. ${ }^{24}$ The amplitude of the sleep-wake rhythm is reduced: older people tend to show less intense activity during their active phase and less sleep during their rest phase. ${ }^{25}$ Total sleep time, however, appears to decrease only slightly or remain stable in healthy aging, with those 60 years and over sleeping an average of 6.5-7 hours a day. ${ }^{26,27}$

Although aging itself does not always bring about changes in sleep quantity, it does cause distinct changes to sleep architecture. ${ }^{28}$ Sleep tends to become shallower, with a greater percentage of the night being spent in the lighter sleep stages (1 and 2); electroencephalogram (EEG) recorded during stage 2 sleep contains fewer sleep spindles and smaller amplitude $\mathrm{K}$ complexes than it does in younger adults. One of the most profound changes is a decrease in the percentage of time spent in slow-wave sleep (stage 3 ), as characterized by a reduction in the number and amplitude of delta waves. ${ }^{29}$ A meta-analysis of 65 studies $^{30}$ showed that in adults, there is a gradual reduction in the percentage of slow-wave sleep, rapid eye movement (REM) sleep latency, and sleep efficiency (time spent sleeping while in bed), and an increase in the percentage of stage 1 and 2 , and wake after sleep onset, up to $\sim 60$ years; after which only sleep efficiency continues to decrease. Despite the many reports that REM sleep decreases with age, ${ }^{30}$ when mental or physical illness are controlled for and various sleep characteristics are measured using polysomnography (PSG) or actigraphy (ie, sleep latency, sleep efficiency, total sleep time, REM sleep latency, wake after sleep onset, etc), the percentage of REM sleep appears to remain relatively stable in old age. ${ }^{30}$

The decreased ability to maintain sleep once initiated, most often linked to some comorbid health condition, appears to be a major factor contributing to the increase in age-associated sleep complaints. ${ }^{28,31,32}$ Insomnia, which is typically defined as self-reported difficulty falling or staying asleep, accompanied by daytime sleepiness, is quite common in older people. Despite the characteristic changes in sleep parameters discussed above, difficulty sleeping might not be an inevitable part of healthy aging, but rather a consequence of other changes that accompany aging. There is an increase in the prevalence of a number of primary sleep disorders with aging. For example, obstructive sleep apnea increases in frequency with age, with prevalence rates as high as $62 \%$ in those over 60 years of age. ${ }^{33}$ Periodic limb movements, which can severely disrupt sleep continuity, and restless legs syndrome, which can delay sleep onset, are also more common in older people. REM sleep behavior disorder (involuntary, sometimes violent, movements during REM sleep, due to loss of muscle atonia) is also more common in older individuals. Interestingly, symptoms of this disorder appear to be present years prior to the diagnosis of Parkinson's disease; up to half of cases of REM sleep behavior disorder are later diagnosed with Parkinson's disease. ${ }^{34}$

In addition, medical or psychiatric conditions may occur in aged individuals that disturb sleep indirectly (eg, prostatitis, loss of bladder elasticity, gastrointestinal disorders, chronic pain syndromes, and depression). ${ }^{28}$ Drug treatments for some conditions that increase in frequency with aging can also disrupt sleep eg, diuretics for patients with hypertension, or antidepressants, especially those said to be "activating".

The increase in sleep disorders and disturbance resulting from associated illnesses or medications may contribute to the degree of sleep disruption experienced by older people. Extensive health assessment can screen out nearly all sleep complaints and disorders in an older population, ${ }^{35}$ providing further support for the link between illness and sleep abnormalities, rather than these disturbances being due to the aging process. Nevertheless, roughly $10 \%$ to $16 \%$ of community-dwelling adults over 65 have been noted to report chronic (primary) insomnia in the absence of an obvious precipitant. ${ }^{36,37}$ Age-associated changes in circadian organization, a decline in health due to aging, and hyperarousal from abnormalities to the hypothalamic-pituitary-adrenal axis appear to be contributing factors. ${ }^{38,39}$ Other biologically associated causes, such as conditions like "insomnia with short sleep duration", may play a role as well. ${ }^{40}$

The timing of sleep and wakefulness is influenced by the interaction between homeostatic sleep propensity and circadian processes, such that the circadian drive for wakefulness during the daytime opposes the gradual buildup of pressure for sleep as waking is sustained. Similarly, the circadian drive for sleep acts in opposition to the declining homeostatic need for sleep during the late part of a night's sleep. ${ }^{41-43}$ The changes observed during aging reflect a decline in the amplitude of signals from the circadian pacemaker to the sleep-wake regulatory regions. ${ }^{44-46}$ For example, one of the most robust circadian clock-controlled rhythms that becomes impaired with age is that of melatonin, a sleep-promoting hormone. ${ }^{47,48}$ The role of melatonin in the aging process is not well understood. Even so, nightly melatonin supplementation, alone or combined with magnesium (which also improves measures of insomnia), ${ }^{49}$ has been shown to improve sleep disturbance in older adults $^{50-52}$ as well as to diminish symptoms of REM sleep 
behavior disorder. ${ }^{53}$ These findings suggest a potential therapeutic role for melatonin in treating sleep disturbance symptoms in older individuals.

With age also comes an increased risk of neurodegenerative disease, the emergence of which often includes a lengthy prodromal period that can include impaired sleep. For example, sleep disturbances and alterations to the sleep-wake cycle have been observed prior to the onset of, not just motor symptoms of Parkinson's disease but notably, other symptoms of Alzheimer's disease ${ }^{54,55}$ and Lewy body dementia, ${ }^{56}$ as well as being common throughout the course of frontotemporal dementia. ${ }^{57}$ This makes it much more difficult to distinguish between normal age-related changes to sleep and changes that are due to an underlying degenerative process. Thus, interpreting sleep disturbances in a "healthy" younger-old population (ie, age 65-80) must be done with caution since these symptoms may be prodromal for the development of neurodegenerative diseases or other illnesses that may not be diagnosed until years later. For example, it remains unclear whether sleep impairment at this stage contributes to an increased risk of neurocognitive disorders later on in older hospitalized patients (eg, delirium).

\section{Methods for the review}

The aim of the present review was to provide a brief, yet comprehensive, overview of current data examining sleep characteristics (ie, quantity, quality, and circadian changes) in samples that included patients 80 years or older, who were admitted to the intensive care unit (ICU). The PubMed database was searched using the following key terms: "sleep", "intensive care unit", "ICU", "80 years", "older", "elderly", and "senior". Excluding reviews, only those studies from the past 10 years that explicitly stated that individuals 80 years and older were included in their sample were considered. The search resulted in 19 studies that met our criteria (Table 1). Relevant studies referenced within these publications that met our criteria but that were older than 10 years were also included in our summary of findings.

\section{Methods for studying sleep in the ICU}

Sleep can be characterized in terms of: quantity (total sleep time and time spent in each stage); quality (wake after sleep onset, EEG patterns, and stage changes); and the circadian distribution (the pattern over a 24 hour cycle). To date, PSG remains the best method for assessing sleep, and although it may be time consuming to set up and may be uncomfortable to wear for critically ill patients, it is the most reliable measure. Accurate recording relies on several measures, including at least three EEG signals, two electrooculography signals, and an electromyography signal from the submentalis muscle. Additional measures are typically recorded and may include oral and/or nasal airflow, abdominal movements, electrocardiogram, and pulse oximetry. ${ }^{58}$ Even so, PSG recordings are not always possible in a critically ill patient, for reasons such as physical limitations and abnormal EEG patterns, including epileptogenic activity, altered consciousness, or various metabolic changes (eg, sepsis, intoxication, or medications). ${ }^{59}$

When PSG is not feasible, several others methods may be employed. The easiest is subjective evaluation of changes in sleep and wake times by nursing staff and/or the patient. Sleep forms are easy to administer and very inexpensive. Even so, nurses have been shown to overestimate sleep time ${ }^{60}$ and may fail to detect changes in patterns. This method also does not provide information about alterations in sleep architecture and may not be possible in all patients, particularly those with altered consciousness. For these individuals, the actigraphy method may be more applicable. Actigraphy involves the use of a wristwatch-like device that is placed on the patient's wrist or ankle and records movements as an indicator of sleep or wakefulness. This is useful in many circumstances but often less so in ICU patients who typically have limited mobility, which may bias results. Actigraphy has also been shown to be a valid alternative for sleep assessment and an indicator of underlying sleep architecture. ${ }^{61}$ Finally, when EEG recording is possible from the frontal electrodes, the bispectral index may provide some information regarding depth of anesthesia (sedation), but it does not give any information about sleep architecture, and data collection is often inconsistent. ${ }^{62}$

\section{Sleep in the ICU}

The ICU provides constant close monitoring of critically ill individuals who are experiencing a serious or life-threatening illness or injury. Sleep disturbance is common in ICU patients, with more than $60 \%$ of patients reporting having poor sleep or being sleep-deprived, when questioned prior to discharge. ${ }^{63,64}$ As assessed using 24-hour polysomnographic recordings, abnormal sleep-wake rhythms, sleep fragmentation, and shortened or absent REM and slow-wave sleep (important restorative components) are prominent features of those in the ICU. ${ }^{60,65-67}$ Sleep disruption in the ICU is recognized as impairing recovery and even contributing to mortality. ${ }^{68,69}$ 
Table I Studies examining sleep in the intensive care unit that have included individuals 80 years and older

\begin{tabular}{|c|c|c|c|}
\hline Study & Sample age range & Sleep measures & Major findings \\
\hline Whitcomb et al99 & $68-83$ & Wireless sleep monitor & $\begin{array}{l}\text { Sedation and lack of REM sleep increased symptoms } \\
\text { of delirium }\end{array}$ \\
\hline Roche-Campo et al ${ }^{100}$ & $25-86$ & PSG & Sleep quality higher during mechanical ventilation \\
\hline Chang et $\mathrm{al}^{101}$ & $65-86$ & Recorded interviews (narratives) & $\begin{array}{l}\text { Continuous sleep disrupted due to constant noise } \\
\text { (eg, equipment, staff) }\end{array}$ \\
\hline Chen et al ${ }^{102}$ & $53-90$ & $\begin{array}{l}\text { PSG; actigraphy; nurse observations; } \\
\text { Stanford Sleepiness Scale }\end{array}$ & $\begin{array}{l}\text { Valerian, acupressure increased sleep time, } \\
\text { decreased wake frequency, decreased sleepiness }\end{array}$ \\
\hline Drouot et al ${ }^{58}$ & $58-85$ & PSG & $\begin{array}{l}\text { Decreased REM sleep, slow EEG activity, impaired } \\
\text { EEG reactivity during wakefulness }\end{array}$ \\
\hline Savi et al ${ }^{103}$ & $35-80$ & $\begin{array}{l}\text { Nottingham Health Profile } \\
\text { self-report questionnaire }\end{array}$ & Inspiratory muscle strength improved sleep quality \\
\hline Zeilani and Seymour ${ }^{104}$ & $19-82$ & Recorded interviews (narratives) & Pain was a contributing factor to sleep disturbance \\
\hline Roche Campo et al ${ }^{105}$ & $72-85$ & PSG & $\begin{array}{l}\text { Noninvasive ventilation failure results in poorer sleep } \\
\text { quality, less REM sleep, and greater circadian disruption }\end{array}$ \\
\hline Kelly and McKinley ${ }^{106}$ & 19-84 & SF-36 & $\begin{array}{l}\text { Interrupted sleep while in the ICU may be due to } \\
\text { frequent interventions, uncomfortable beds or noise } \\
\text { from machinery, conversations or other patients; } \\
\text { survivors perceived good health despite disturbed } \\
\text { sleep during recovery }\end{array}$ \\
\hline Beecroft et a $\left.\right|^{107}$ & $55-80$ & PSG; actigraphy; nurse assessment & $\begin{array}{l}\text { Decreased total sleep time and sleep efficiency, } \\
\text { high frequency of awakenings; elevated stage I and } \\
\text { decreased REM sleep; highly fragmented sleep }\end{array}$ \\
\hline Bourne et al ${ }^{108}$ & $46-82$ & $\begin{array}{l}\text { Bispectral index; actigraphy; nurse } \\
\text { assessment; patient self-report } \\
\text { (Richards Campbell Sleep } \\
\text { Questionnaire) }\end{array}$ & Melatonin increased nocturnal sleep by I hour \\
\hline Cabello et al ${ }^{109}$ & $47-85$ & PSG & $\begin{array}{l}\text { Mechanical ventilation was associated with short REM } \\
\text { sleep and increased sleep architecture fragmentation }\end{array}$ \\
\hline Friese et $\mathrm{al}^{\prime 10}$ & $20-83$ & PSG & $\begin{array}{l}\text { Average total sleep time was } 8.23 \text { hours; } 6.2 \text { hours of } \\
\text { awakenings; reduced stages } 3 \text { and } 4 \text {, and REM }\end{array}$ \\
\hline Hweidi"l' & $35-80$ & $\begin{array}{l}\text { Intensive Care Environmental } \\
\text { Stressor Scale }\end{array}$ & $\begin{array}{l}\text { Not being able to sleep was perceived as a primary } \\
\text { stressor }\end{array}$ \\
\hline Toublanc et al ${ }^{1 / 2}$ & $42-81$ & PSG & $\begin{array}{l}\text { Assist-control ventilation was associated with } \\
\text { increased stages I and } 2 \text {, and reduced wakefulness } \\
\text { during first half of night; increased stages } 3 \text { and } \\
4 \text { during the second half of night }\end{array}$ \\
\hline Hellgren and Ståhle ${ }^{1 / 3}$ & $35-85$ & SF-36 & No change \\
\hline Olofsson et al ${ }^{80}$ & $52-83$ & $\begin{array}{l}\text { Melatonin secretion; nurse } \\
\text { assessment (Sedation-Agitation } \\
\text { Scale); bispectral index }\end{array}$ & $\begin{array}{l}\text { Circadian rhythm of melatonin was abolished during } \\
\text { deep sedation and mechanical ventilation }\end{array}$ \\
\hline Tamburri et al ${ }^{114}$ & $48-84$ & Nurse activity checklist & $\begin{array}{l}\text { High frequency of nocturnal care leaves few } \\
\text { opportunities for uninterrupted sleep }\end{array}$ \\
\hline Frisk et $\mathrm{al}^{77}$ & $4 I-88$ & Melatonin secretion & $\begin{array}{l}\text { Mechanical ventilation was association with } \\
\text { decreased melatonin secretion }\end{array}$ \\
\hline Frisk and Nordström ${ }^{76}$ & $19-85$ & $\begin{array}{l}\text { Nurse and patient questionnaire } \\
\text { (Richards Campbell Sleep } \\
\text { Questionnaire); patient interview }\end{array}$ & $\begin{array}{l}\text { Hypnotics/sedatives results in poorer sleep scores; } \\
\text { No difference between nurse and patient reports }\end{array}$ \\
\hline Freedman et $a^{65}$ & $20-83$ & PSG & $\begin{array}{l}\text { Environmental noise is partly responsible for } \\
\text { qualitative reports of sleep disruption }\end{array}$ \\
\hline Freedman et $a^{63}$ & $19-86$ & Self-report questionnaire & $\begin{array}{l}\text { Poor sleep quality and daytime sleepiness is } \\
\text { commonly reported in ICU settings }\end{array}$ \\
\hline
\end{tabular}

Abbreviations: EEG, electroencephalogram; ICU, intensive care unit; PSG, polysomnography; REM, rapid eye movement; SF-36, self-report 36-item short-form health survey.

Various factors can influence sleep in the ICU..$^{59,70-73}$ Despite the link between sleep and recovery from illness, the ICU can be a noisy and chaotic environment, which can have a significant negative impact on sleep; however, less than $30 \%$ of awakenings in the ICU are reportedly due to environmental noise. ${ }^{65,74}$ Sleep disturbance in the ICU appears to be due to a combination of environmental factors, including noise, light exposure at night (which can suppress melatonin), 
room temperature, routines of caretaking staff, and the impacts of mechanical ventilation, along with factors such as medications that may disrupt or promote sleep. ${ }^{75}$

In addition to these environmental factors, endogenous mechanisms related to the illness itself, such as immune system responses to illness and pain or discomfort associated with the illness or with treatment interventions, ${ }^{76}$ may disrupt sleep in patients whose sleep-regulatory and circadian systems may already be compromised. Altered circadian patterns of melatonin or virtually nonexistent secretion have also been noted in ICU patients. ${ }^{77,78}$ This abnormality is associated with mood and sleep disorders that are observed in elderly hospitalized patients ${ }^{79}$ and may contribute to slower recovery in the critically ill. ${ }^{80}$ Melatonin supplementation may serve as a promising new way to manage sleep disruption and delirium in the ICU; however, the research in this area is sparse ${ }^{81}$ It is important for the critically ill to receive sufficient sleep as well as good sleep quality. Good quality sleep can contribute, along with other mechanisms, to more efficient and timely recovery and prevent possible negative outcomes. ${ }^{59,82,83}$

Poor sleep can contribute to the onset of delirium, which occurs in up to $80 \%$ of ICU patients. ${ }^{84}$ Delirium is characterized as a transient state of confusion and disorientation with fluctuating intensity, often accompanied by cognitive impairment. Delirium is a strong predictor of longer ICU length of stay, mechanical ventilation use, and even mortality. ${ }^{85}$ Sleep deprivation can result in delirium-like symptoms, such as inattention and fluctuations in mental capacity; however, it is still unclear whether sleep disruption in the ICU is a cause, consequence, or comorbidity of delirium. That said, sleep disturbance appears to be a potential risk factor by interacting with various neurobiological systems that are involved in delirium. ${ }^{86,87}$

\section{Sleep in ICU patients aged $\geq 80$ years}

Increasing age is often accompanied by an increased risk of adverse health outcomes. This is particularly true of those $\geq 80$ years, who exhibit a higher prevalence of illness and ICU admission compared with younger adults. ${ }^{88,89} \mathrm{With}$ this comes a higher level of frailty or an increased vulnerability to poor outcomes, due to the accumulation of ageassociated declines in the physiological reserve of multiple systems. ${ }^{90,91}$ Despite the importance of sleep to good health, the relationship between frailty and sleep disturbance has been sparsely studied ${ }^{92,93}$ and primarily among communitydwelling older adults. ${ }^{14,94-97}$ One recent study demonstrated that nonfrail men 65 years and older (mean 75.7 years) who exhibited poor subjective sleep quality, increased nighttime waking, and greater nighttime hypoxemia were at high risk for showing increased frailty levels approximately 3 years later. ${ }^{96}$ In the same sample, men who exhibited excessive daytime sleepiness, frequent nighttime awakenings, and sleep apnea were also at a greater risk for mortality. ${ }^{96}$ Even so, overall health status, independent of daytime sleepiness and sleep disturbance, appears to be a stronger determinant when assessing risk of death. ${ }^{14,98}$

How age itself impacts sleep in ICU patients is not yet clear. First, many studies that have examined sleep in the ICU do not report the age range of their sample. Since sleep characteristics and recovery processes can vary over the course of the lifespan, the extent to which sleep disturbance affects recovery in elderly ICU patients remains unclear, as does the nature of the sleep disturbance, particularly in the oldest of old ( $\geq 80$ years). Second, even in those studies that do report age, there is often a wide age range (eg, 19-88 years). ${ }^{76,80,99-114}$ Third, the few studies that have examined the relationship between age and sleep in older adults in the ICU have failed to find an association between increasing age and sleep quality, ${ }^{63,65}$ even when analyses were stratified into young-old ( $<75$ years) and older-old (>75 years). ${ }^{76}$ This observation might reflect the fact that sleep parameters change only modestly in people over age 60 years, so sleep processes might be similarly affected by the ICU environment across this age range. The impact that age has on sleep in this population, especially with regards to health outcomes, is unknown because so few studies have examined this issue. In addition, other than Freedman et $\mathrm{al}^{63}$ who excluded those with a history of dementia, other studies that included those $\geq 80$ years did not take into account the potential influence of underlying causes, such as neurodegenerative disease.

Sleep disturbance and insomnia are generally quite prevalent in older hospitalized patients, ${ }^{115}$ which is reflected in the high rate of sedative-hypnotic drug prescriptions given to this population. Up to $41 \%$ and $96 \%$ of older patients in general and surgical wards, respectively, receive such prescriptions. ${ }^{116,117}$ These drugs tend to have greater negative effects in older individuals ${ }^{118}$ and might interact with other commonly prescribed medications (eg, those for blood pressure, cholesterol, and dementia), as well as increase the risk of falls, delirium, and rebound insomnia. Often, the small benefit that sedative-hypnotics have in this population does not justify the increased risk of adverse health outcomes, ${ }^{119}$ even following ICU admittance. ${ }^{85}$ 
Taken together, these findings suggest that sleep disturbance might have prognostic utility in predicting future increases in frailty and a decline in health; however, the nature of this utility has not been examined - definitely not in ICU patients. One potential area, discussed above, that deserves further exploration is the role of melatonin. It is not possible to make recommendations at this time for the clinical use of melatonin in the ICU, due to the lack of well-designed randomized, controlled trials that take into account the effects of aging and other physical or psychiatric conditions; this is especially needed in those $\geq 80$ years, who are often excluded from clinical trials. The interplay between sleep, circadian rhythms, frailty, and health outcomes of the critically ill oldest of old in the ICU remains unclear. It is also uncertain whether reducing sleep disturbance (eg, possibly by restoring normal nocturnal melatonin levels) in seriously ill patients can have a beneficial impact on their health outcomes. These questions should take precedence in our attempt to understand the reasons behind declining health in critically ill, hospitalized older individuals, and how it can be prevented.

\section{Conclusion}

Despite our increasing understanding of how hospitalization affects the sleep patterns of patients, there is still little known about the unique impact that critical care has on these parameters in the most frail and oldest of old. More work is required to determine whether and how these disturbances influence health outcomes, such as cognitive decline and mortality, of the seriously ill elderly. It is also crucial to understand how each patient's level of frailty interacts with these disturbances. For example, even a mild degree of impairment can lead to significant health decline in one individual but not in another with similar impairment. Does sleep disturbance contribute to, or determine, such outcomes?

Recognizing which aspects of health are associated with adverse outcomes can create better diagnostic measures that will capture these risk patterns. Greater awareness of these risks amongst health care professionals might decrease the chances of adverse outcomes in those admitted to the ICU; awareness may also guide more appropriate emergency treatment for those who are critically ill, which may include not undertaking certain medical treatments that will put the patient at risk of further decline or death. Ultimately, studies should be undertaken to establish potential intervention strategies to delay or prevent a decline in health status following ICU admission; these studies should include rigorous trials of interventions to improve sleep, as a potentially important factor that can affect healing and recovery. ${ }^{59}$ Such studies should also specifically include older adults, who commonly experience health declines in the ICU with a high rate of adverse outcomes but who, even so, often are excluded from clinical trials. ${ }^{18,120}$

\section{Disclosure}

The authors report no conflicts of interest in this work.

\section{References}

1. Knutsson A. Health disorders of shift workers. Occup Med (Lond). 2003;53(2):103-108.

2. Cappuccio FP, Taggart FM, Kandala NB, et al. Meta-analysis of short sleep duration and obesity in children and adults. Sleep. 2008;31(5):619-626.

3. Puttonen S, Härmä M, Hublin C. Shift work and cardiovascular disease - pathways from circadian stress to morbidity. Scand J Work Environ Health. 2010;36(2):96-108.

4. Rüger M, Scheer FA. Effects of circadian disruption on the cardiometabolic system. Rev Endocr Metab Disord. 2009;10(4): 245-260.

5. Kolstad HA. Nightshift work and risk of breast cancer and other cancers - a critical review of the epidemiologic evidence. Scand $J$ Work Environ Health. 2008;34(1):5-22.

6. Megdal SP, Kroenke CH, Laden F, Pukkala E, Schernhammer ES. Night work and breast cancer risk: a systematic review and meta-analysis. Eur J Cancer. 2005;41(13):2023-2032.

7. Gamaldo CE, Shaikh AK, McArthur JC. The sleep-immunity relationship. Neurol Clin. 2012;30(4):1313-1343.

8. Palmblad J, Petrini B, Wasserman J, Akerstedt T. Lymphocyte and granulocyte reactions during sleep deprivation. Psychosom Med. 1979;41(4):273-278.

9. Walker MP. Cognitive consequences of sleep and sleep loss. Sleep Med. 2008;9 Suppl 1:S29-S34.

10. Buxton OM, Pavlova M, Reid EW, Wang W, Simonson DC, Adler GK. Sleep restriction for 1 week reduces insulin sensitivity in healthy men. Diabetes. 2010;59(9):2126-2133.

11. Omisade A, Buxton OM, Rusak B. Impact of acute sleep restriction on cortisol and leptin levels in young women. Physiol Behav. 2010;99(5):651-656.

12. Spiegel K, Knutson K, Leproult R, Tasali E, Van Cauter E. Sleep loss: a novel risk factor for insulin resistance and Type 2 diabetes. $J$ Appl Physiol (1985). 2005;99(5):2008-2019.

13. Lim AS, Kowgier M, Yu L, Buchman AS, Bennett DA. Sleep fragmentation and the risk of incident Alzheimer's disease and cognitive decline in older persons. Sleep. 2013;36(7):1027-1032.

14. Sterniczuk R, Theou O, Rusak B, Rockwood K. Sleep disturbance is associated with incident dementia and mortality. Curr Alzheimer Res. 2013;10(7):767-775.

15. Adam K, Oswald I. Sleep helps healing. Br Med J (Clin Res Ed). 1984;289(6456):1400-1401.

16. Evans JC, French DG. Sleep and healing in intensive care settings. Dimens Crit Care Nurs. 1995;14(4):189-199.

17. Strahan EH, Brown RJ. A qualitative study of the experiences of patients following transfer from intensive care. Intensive Crit Care Nurs. 2005;21(3):160-171.

18. Clegg A, Young J, Iliffe S, Rikkert MO, Rockwood K. Frailty in elderly people. Lancet. 2013;381(9868):752-762.

19. Mitnitski A, Song X, Rockwood K. Assessing biological aging: the origin of deficit accumulation. Biogerontology. 2013;14(6):709-717.

20. Hammond EC. Some preliminary findings on physical complaints from a prospective study of 1,064,004 men and women. Am J Public Health Nations Health. 1964;54:11-23. 
21. Karacan I, Thornby JI, Anch M, et al. Prevalence of sleep disturbance in a primarily urban Florida County. Soc Sci Med. 1976; 10(5):239-244.

22. Kripke DF, Simons RN, Garfinkel L, Hammond EC. Short and long sleep and sleeping pills. Is increased mortality associated? Arch Gen Psychiatry. 1979;36(1):103-116.

23. Foley DJ, Monjan AA, Brown SL, Simonsick EM, Wallace RB, Blazer DG. Sleep complaints among elderly persons: an epidemiologic study of three communities. Sleep. 1995;18(6):425-432.

24. Kripke DF, Youngstedt SD, Elliott JA, et al. Circadian phase in adults of contrasting ages. Chronobiol Int. 2005;22(4):695-709.

25. Monk TH. Aging human circadian rhythms: conventional wisdom may not always be right. J Biol Rhythms. 2005;20(4):366-374

26. National Sleep Foundation. 2003 Sleep in America Poll. Washington, DC: National Sleep Foundation; 2003. Available from: http:// sleepfoundation.org/sites/default/files/2003SleepPollExecSumm.pdf. Accessed April 6, 2014.

27. Rajput V, Bromley SM. Chronic insomnia: a practical review. Am Fam Physician. 1999;60(5):1431-1438; discussion: 1441-1442.

28. Ancoli-Israel S, Ayalon L, Salzman C. Sleep in the elderly: normal variations and common sleep disorders. Harv Rev Psychiatry. 2008; 16(5):279-286.

29. Crowley K. Sleep and sleep disorders in older adults. Neuropsychol Rev. 2011;21(1):41-53.

30. Ohayon MM, Carskadon MA, Guilleminault C, Vitiello MV. Metaanalysis of quantitative sleep parameters from childhood to old age in healthy individuals: developing normative sleep values across the human lifespan. Sleep. 2004;27(7):1255-1273.

31. Wolkove N, Elkholy O, Baltzan M, Palayew M. Sleep and aging: 1. Sleep disorders commonly found in older people. CMAJ. 2007;176(9):1299-1304.

32. Wolkove N, Elkholy O, Baltzan M, Palayew M. Sleep and aging: 2. Management of sleep disorders in older people. CMAJ. 2007; 176(10):1449-1454.

33. Ancoli-Israel S, Ayalon L. Diagnosis and treatment of sleep disorders in older adults. Am J Geriatr Psychiatry. 2006;14(2):95-103.

34. Gagnon JF, Bédard MA, Fantini ML, et al. REM sleep behavior disorder and REM sleep without atonia in Parkinson's disease. Neurology. 2002;59(4):585-589.

35. Vitiello MV, Moe KE, Prinz PN. Sleep complaints cosegregate with illness in older adults: clinical research informed by and informing epidemiological studies of sleep. J Psychosom Res. 2002;53(1): 555-559.

36. Foley D, Ancoli-Israel S, Britz P, Walsh J. Sleep disturbances and chronic disease in older adults: results of the 2003 National Sleep Foundation Sleep in America Survey. J Psychosom Res. 2004;56(5): 497-502.

37. López-Torres Hidalgo J, Navarro Bravo B, Párraga Martínez I, Andrés Pretel F, Téllez Lapeira J, Boix Gras C. Understanding insomnia in older adults. Int J Geriatr Psychiatry. 2012;27(10):1086-1093.

38. Alessi C, Vitiello MV. Insomnia (primary) in older people. Clin Evid (Online). 2011;2011:2302.

39. Roth T, Roehrs T. Insomnia: epidemiology, characteristics, and consequences. Clin Cornerstone. 2003;5(3):5-15.

40. Vgontzas AN, Fernandez-Mendoza J, Liao D, Bixler EO. Insomnia with objective short sleep duration: the most biologically severe phenotype of the disorder. Sleep Med Rev. 2013;17(4):241-254.

41. Daan S, Beersma DG, Borbély AA. Timing of human sleep: recovery process gated by a circadian pacemaker. Am J Physiol. 1984;246(2 Pt 2): R161-R183.

42. Dijk DJ, Czeisler CA. Contribution of the circadian pacemaker and the sleep homeostat to sleep propensity, sleep structure, electroencephalographic slow waves, and sleep spindle activity in humans. J Neurosci. 1995;15(5 Pt 1):3526-3538

43. Fuller PM, Gooley JJ, Saper CB. Neurobiology of the sleep-wake cycle: sleep architecture, circadian regulation, and regulatory feedback. J Biol Rhythms. 2006;21(6):482-493.
44. Cajochen C, Münch M, Knoblauch V, Blatter K, Wirz-Justice A. Agerelated changes in the circadian and homeostatic regulation of human sleep. Chronobiol Int. 2006;23(1-2):461-474.

45. Hofman MA, Swaab DF. Living by the clock: the circadian pacemaker in older people. Ageing Res Rev. 2006;5(1):33-51.

46. Kalsbeek A, Yi CX, la Fleur SE, Buijs RM, Fliers E. Suprachiasmatic nucleus and autonomic nervous system influences on awakening from sleep. Int Rev Neurobiol. 2010;93:91-107.

47. Benarroch EE. Suprachiasmatic nucleus and melatonin: reciprocal interactions and clinical correlations. Neurology. 2008;71(8):594-598.

48. Karasek M. Melatonin, human aging, and age-related diseases. Exp Gerontol. 2004;39(11-12):1723-1729.

49. Abbasi B, Kimiagar M, Sadeghniiat K, Shirazi MM, Hedayati M, Rashidkhani B. The effect of magnesium supplementation on primary insomnia in elderly: A double-blind placebo-controlled clinical trial. $J$ Res Med Sci. 2012;17(12):1161-1169.

50. Lyseng-Williamson KA. Melatonin prolonged release: in the treatment of insomnia in patients aged $\geq 55$ years. Drugs Aging. 2012;29(11):911-923.

51. Riemersma-van der Lek RF, Swaab DF, Twisk J, Hol EM, Hoogendijk WJ, Van Someren EJ. Effect of bright light and melatonin on cognitive and noncognitive function in elderly residents of group care facilities: a randomized controlled trial. JAMA. 2008; 299(22):2642-2655

52. Rondanelli M, Opizzi A, Monteferrario F, Antoniello N, Manni R, Klersy $\mathrm{C}$. The effect of melatonin, magnesium, and zinc on primary insomnia in long-term care facility residents in Italy: a double-blind, placebo-controlled clinical trial. J Am Geriatr Soc. 2011;59(1): 82-90

53. McCarter SJ, Boswell CL, St Louis EK, et al. Treatment outcomes in REM sleep behavior disorder. Sleep Med. 2013;14(3):237-242.

54. Sterniczuk R, Dyck RH, Laferla FM, Antle MC. Characterization of the 3xTg-AD mouse model of Alzheimer's disease: part 1. Circadian changes. Brain Res. 2010;1348:139-148.

55. Tranah GJ, Blackwell T, Stone KL, et al; SOF Research Group. Circadian activity rhythms and risk of incident dementia and mild cognitive impairment in older women. Ann Neurol. 2011;70(5):722-732.

56. Guarnieri B, Adorni F, Musicco M, et al. Prevalence of sleep disturbances in mild cognitive impairment and dementing disorders: a multicenter Italian clinical cross-sectional study on 431 patients. Dement Geriatr Cogn Disord. 2012;33(1):50-58.

57. Anderson KN, Hatfield C, Kipps C, Hastings M, Hodges JR. Disrupted sleep and circadian patterns in frontotemporal dementia. Eur J Neurol. 2009;16(3):317-323.

58. Drouot X, Roche-Campo F, Thille AW, et al. A new classification for sleep analysis in critically ill patients. Sleep Med. 2012;13(1): 7-14.

59. Boyko Y, Ording H, Jennum P. Sleep disturbances in critically ill patients in ICU: how much do we know? Acta Anaesthesiol Scand. 2012;56(8):950-958.

60. Aurell J, Elmqvist D. Sleep in the surgical intensive care unit: continuous polygraphic recording of sleep in nine patients receiving postoperative care. Br Med J (Clin Res Ed). 1985;290(6474): 1029-1032.

61. Tryon WW. Issues of validity in actigraphic sleep assessment. Sleep. 2004;27(1):158-165.

62. LeBlanc JM, Dasta JF, Kane-Gill SL. Role of the bispectral index in sedation monitoring in the ICU. Ann Pharmacother. 2006;40(3):490-500.

63. Freedman NS, Kotzer N, Schwab RJ. Patient perception of sleep quality and etiology of sleep disruption in the intensive care unit. Am J Respir Crit Care Med. 1999;159(4 Pt 1):1155-1162.

64. Simini B. Patients' perceptions of intensive care. Lancet. 1999; 354(9178):571-572.

65. Freedman NS, Gazendam J, Levan L, Pack AI, Schwab RJ. Abnormal sleep/wake cycles and the effect of environmental noise on sleep disruption in the intensive care unit. Am J Respir Crit Care Med. 2001;163(2):451-457. 
66. Hardin KA, Seyal M, Stewart T, Bonekat HW. Sleep in critically ill chemically paralyzed patients requiring mechanical ventilation. Chest. 2006;129(6):1468-1477.

67. Hilton BA. Quantity and quality of patients' sleep and sleepdisturbing factors in a respiratory intensive care unit. $J$ Adv Nurs. 1976;1(6):453-468.

68. Dew MA, Hoch CC, Buysse DJ, et al. Healthy older adults' sleep predicts all-cause mortality at 4 to 19 years of follow-up. Psychosom Med. 2003;65(1):63-73.

69. Eddleston JM, White P, Guthrie E. Survival, morbidity, and quality of life after discharge from intensive care. Crit Care Med. 2000;28(7):2293-2299.

70. Elliott R, McKinley S, Cistulli P. The quality and duration of sleep in the intensive care setting: an integrative review. Int J Nurs Stud. 2011;48(3):384-400.

71. Hardin KA. Sleep in the ICU: potential mechanisms and clinical implications. Chest. 2009;136(1):284-294.

72. Matthews EE, (2011). Sleep disturbances and fatigue in critically ill patients. AACN Adv Crit Care. 2011;22(3):204-224.

73. Tembo AC, Parker V. Factors that impact on sleep in intensive care patients. Intensive Crit Care Nurs. 2009;25(6):314-322.

74. Gabor JY, Cooper AB, Crombach SA, et al. Contribution of the intensive care unit environment to sleep disruption in mechanically ventilated patients and healthy subjects. Am J Respir Crit Care Med. 2003;167(5):708-715.

75. Kamdar BB, Needham DM, Collop NA. Sleep deprivation in critical illness: its role in physical and psychological recovery. J Intensive Care Med. 2012;27(2):97-111.

76. Frisk U, Nordström G. Patients' sleep in an intensive care unit patients' and nurses' perception. Intensive Crit Care Nurs. 2003;19(6):342-349.

77. Frisk U, Olsson J, Nylén P, Hahn RG. Low melatonin excretion during mechanical ventilation in the intensive care unit. Clin Sci (Lond). 2004;107(1):47-53.

78. Mundigler G, Delle-Karth G, Koreny M, et al. Impaired circadian rhythm of melatonin secretion in sedated critically ill patients with severe sepsis. Crit Care Med. 2002;30(3):536-540.

79. Baskett JJ, Cockrem JF, Todd MA. Melatonin levels in hospitalized elderly patients: a comparison with community based volunteers. Age Ageing. 1991;20(6):430-434

80. Olofsson K, Alling C, Lundberg D, Malmros C. Abolished circadian rhythm of melatonin secretion in sedated and artificially ventilated intensive care patients. Acta Anaesthesiol Scand. 2004;48(6):679-684.

81. Bellapart J, Boots R. Potential use of melatonin in sleep and delirium in the critically ill. Br J Anaesth. 2012;108(4):572-580.

82. Carpentieri A, Díaz de Barboza G, Areco V, Peralta López M, Tolosa de Talamoni N. New perspectives in melatonin uses. Pharmacol Res. 2012;65(4):437-444.

83. Mantz J, Paugam-Burtz C, Hamada S. Do sleep disorders have an impact on outcome in ICU patients? In: Vincent JL, editor. Yearbook of Intensive Care and Emergency Medicine 2010. Berlin: Springer-Verlag; 2010:571-580.

84. Faria Rda S, Moreno RP. Delirium in intensive care: an under-diagnosed reality. Rev Bras Ter Intensiva. 2013;25(2):137-147.

85. Pandharipande P, Ely EW. Sedative and analgesic medications: risk factors for delirium and sleep disturbances in the critically ill. Crit Care Clin. 2006;22(2):313-327, vii.

86. Figueroa-Ramos MI, Arroyo-Novoa CM, Lee KA, Padilla G, Puntillo KA. Sleep and delirium in ICU patients: a review of mechanisms and manifestations. Intensive Care Med. 2009;35(5): 781-795.

87. Weinhouse GL, Schwab RJ, Watson PL, et al. Bench-to-bedside review: delirium in ICU patients - importance of sleep deprivation. Crit Care. 2009;13(6):234.

88. Mullins PM, Goyal M, Pines JM. National growth in intensive care unit admissions from emergency departments in the United States from 2002 to 2009. Acad Emerg Med. 2013;20(5):479-486.
89. Nguyen YL, Angus DC, Boumendil A, Guidet B. The challenge of admitting the very elderly to intensive care. Ann Intensive Care. 2011;1(1):29.

90. Rockwood K, Mogilner A, Mitnitski A. Changes with age in the distribution of a frailty index. Mech Ageing Dev. 2004;125(7):517-519.

91. Rockwood K, Mitnitski A. Frailty in relation to the accumulation of deficits. J Gerontol A Biol Sci Med Sci. 2007;62(7):722-727.

92. Cochen V, Arbus C, Soto ME, et al. Sleep disorders and their impacts on healthy, dependent, and frail older adults. J Nutr Health Aging. 2009;13(4):322-329.

93. Mehra R. Failing sleep? Beware of frailty or death. Sleep Med. 2012;13(10):1211-1212.

94. Endeshaw YW, Unruh ML, Kutner M, Newman AB, Bliwise DL. Sleep-disordered breathing and frailty in the Cardiovascular Health Study Cohort. Am J Epidemiol. 2009;170(2):193-202.

95. Ensrud KE, Blackwell TL, Redline S, et al; Osteoporotic Fractures in Men Study Group. Sleep disturbances and frailty status in older community-dwelling men. J Am Geriatr Soc. 2009;57(11):2085-2093.

96. Ensrud KE, Blackwell TL, Ancoli-Israel S, et al. Sleep disturbances and risk of frailty and mortality in older men. Sleep Med. 2012;13(10):1217-1225

97. Vaz Fragoso CA, Gahbauer EA, Van Ness PH, Gill TM. Sleep-wake disturbances and frailty in community-living older persons. $J \mathrm{Am}$ Geriatr Soc. 2009;57(11):2094-2100.

98. Rockwood K, Davis HS, Merry HR, MacKnight C, McDowell I. Sleep disturbances and mortality: results from the Canadian Study of Health and Aging. J Am Geriatr Soc. 2001;49(5):639-641.

99. Whitcomb JJ, Morgan M, Irvin T, et al. A pilot study on delirium in the intensive care unit: a creative inquiry project with undergraduate nursing students. Dimens Crit Care Nurs. 2013;32(5):266-270.

100. Roche-Campo F, Thille AW, Drouot X, et al. Comparison of sleep quality with mechanical versus spontaneous ventilation during weaning of critically III tracheostomized patients. Crit Care Med. 2013;41(7):1637-1644.

101. Chang CW, Chen YM, Su CC. Care needs of older patients in the intensive care units. J Clin Nurs. 2012;21(5-6):825-832.

102. Chen JH, Chao YH, Lu SF, Shiung TF, Chao YF. The effectiveness of valerian acupressure on the sleep of ICU patients: a randomized clinical trial. Int J Nurs Stud. 2012;49(8):913-920.

103. Savi A, Teixeira C, Silva JM, et al; Gaúcho Weaning Study Group. Weaning predictors do not predict extubation failure in simple-towean patients. J Crit Care. 2012;27(2):221.e1-221.e8.

104. Zeilani R, Seymour JE. Muslim women's narratives about bodily change and care during critical illness: a qualitative study. J Nurs Scholarsh. 2012;44(1):99-107.

105. Roche Campo F, Drouot X, Thille AW, et al. Poor sleep quality is associated with late noninvasive ventilation failure in patients with acute hypercapnic respiratory failure. Crit Care Med. 2010;38(2):477-485.

106. Kelly MA, McKinley S. Patients' recovery after critical illness at early follow-up. J Clin Nurs. 2010;19(5-6):691-700.

107. Beecroft JM, Ward M, Younes M, Crombach S, Smith O, Hanly PJ. Sleep monitoring in the intensive care unit: comparison of nurse assessment, actigraphy and polysomnography. Intensive Care Med. 2008;34(11):2076-2083.

108. Bourne RS, Mills GH, Minelli C. Melatonin therapy to improve nocturnal sleep in critically ill patients: encouraging results from a small randomised controlled trial. Crit Care. 2008;12(2):R52.

109. Cabello B, Thille AW, Drouot X, et al. Sleep quality in mechanically ventilated patients: comparison of three ventilatory modes. Crit Care Med. 2008;36(6):1749-1755.

110. Friese RS, Diaz-Arrastia R, McBride D, Frankel H, Gentilello LM. Quantity and quality of sleep in the surgical intensive care unit: are our patients sleeping? J Trauma. 2007;63(6):1210-1214.

111. Hweidi IM. Jordanian patients' perception of stressors in critical care units: a questionnaire survey. Int J Nurs Stud. 2007;44(2): 227-235. 
112. Toublanc B, Rose D, Glérant JC, et al. Assist-control ventilation vs low levels of pressure support ventilation on sleep quality in intubated ICU patients. Intensive Care Med. 2007;33(7):1148-1154.

113. Hellgren L, Ståhle E. Quality of life after heart valve surgery with prolonged intensive care. Ann Thorac Surg. 2005;80(5):1693-1698.

114. Tamburri LM, DiBrienza R, Zozula R, Redeker NS. Nocturnal care interactions with patients in critical care units. Am J Crit Care. 2004;13(2):102-112; quiz 114.

115. Flaherty JH. Insomnia among hospitalized older persons. Clin Geriatr Med. 2008;24(1):51-67, vi.

116. O'Reilly R, Rusnak C. The use of sedative-hypnotic drugs in a university teaching hospital. CMAJ. 1990;142(6):585-589.
117. Zisselman MH, Rovner BW, Yuen EJ, Louis DZ. Sedative-hypnotic use and increased hospital stay and costs in older people. J Am Geriatr Soc. 1996;44(11):1371-1374.

118. Brandt NJ, Piechocki JM. Treatment of insomnia in older adults: re-evaluating the benefits and risks of sedative hypnotic agents. J Gerontol Nurs. 2013;39(4):48-54.

119. Glass J, Lanctôt KL, Herrmann N, Sproule BA, Busto UE. Sedative hypnotics in older people with insomnia: meta-analysis of risks and benefits. BMJ. 2005;331(7526):1169.

120. Lindley RI. Drug trials for older people. J Gerontol A Biol Sci Med Sci. 2012;67(2):152-157.
Clinical Interventions in Aging

\section{Publish your work in this journal}

Clinical Interventions in Aging is an international, peer-reviewed journal focusing on evidence-based reports on the value or lack thereof of treatments intended to prevent or delay the onset of maladaptive correlates of aging in human beings. This journal is indexed on PubMed Central, MedLine,
Dovepress

CAS, Scopus and the Elsevier Bibliographic databases. The manuscript management system is completely online and includes a very quick and fair peer-review system, which is all easy to use. Visit http://www.dovepress. com/testimonials.php to read real quotes from published authors. 